\title{
The Effect of Glosses on Incidental Vocabulary Learning of Iranian EFL learners
}

\author{
Abbas Moradan \\ Semnan University, Semnan, Iran \\ E-mail: amoradan@semnan.ac.ir \\ Maryam Vafaei (Corresponding author) \\ Semnan University, Semnan, Iran \\ E-mail: mvafaee@semnan.ac.ir
}

Received: 12-05-2016

Published: 01-11-2016
Accepted: 18-07-2016

doi:10.7575/aiac.ijalel.v.5n.6p.34
Advance Access Published: September 2016

URL: http://dx.doi.org/10.7575/aiac.ijalel.v.5n.6p.34

\begin{abstract}
Reading passages contain many new words. Looking up every word in the dictionary and finding the exact meaning can be a difficult job for learners and may hinder the process of reading. Providing glosses can help learners deal with this issue. The objective of the present study is to make enquiries about the effect of glosses on incidental vocabulary learning. To this end, 45 Iranian EFL learners were selected from 70 according to their performance on KET test. Then they were divided into three groups of 15 randomly. Ten reading texts were selected and unfamiliar vocabularies were glossed in three ways: pictorial, textual and pictorial-textual glosses. Participants were required to read the texts under one of the three conditions. After the completion of ten sessions of treatment, participants were given a vocabulary posttest to measure vocabulary learning. The outcome of the study indicated that the group that received the combination of pictorial and textual glosses outperformed the other two groups. The findings can be of great importance for language teachers and material developers.
\end{abstract}

Keywords: Incidental vocabulary learning, Gloss, Pictorial gloss, Textual gloss, Pictorial and textual gloss

\section{Introduction}

Vocabulary is the basic building block in language and lack of these blocks leads to difficulties in using and understanding language. The role of vocabulary in reading is undeniable. Understanding a text may be a difficult task, since it may contain words that the reader does not know their meaning. Therefore vocabulary knowledge is an essential part of language learning. It has an important role in reading and communication. Everyday learners hear or read many new words that perhaps they cannot grasp the meaning of all these new words, so they have to decide which ones they need to focus and learn.

Vocabulary is also an important element in instructional design. Since it's a tough job to teach vocabulary many techniques and strategies are developed to enhance vocabulary learning. One of these techniques that can help readers to understand new and unfamiliar words' meaning is glossing, which makes comprehension more effective. According to Xu Hong (2010), " A gloss is a translation or brief explanation of difficult or technical text (e.g. unusual words) (Segler, 2001)" (p. 60). Glosses are usually placed in the side or bottom margins for 'unfamiliar' words (Lomicka, 1998). They facilitate the reading process.

Most of the times learners are reluctant to use a dictionary and check the meaning of each new word since using the dictionary takes too much time and interferes with the reading process. Sometimes the learner looks up the new word in the dictionary but cannot understand which meaning is appropriate and intended. So he or she may misinterpret the whole text or passage. Even the learner may become unmotivated. But the gloss facilitates the reading process especially when the text is long and difficult. It saves time and the learner will understand the exact meaning of word in the context it is used. In reading a text, students often rely on teacher to provide them with meanings, definitions, or synonyms of unfamiliar vocabularies. But with the help of gloss students will become autonomous readers. Adding gloss and annotation can be a good technique to solve the present problems which will add variety to teaching methods and facilitates reading comprehension.

Schmidt (1995) in his theory called Noticing Theory states that conscious attention is essential for learning. He believes that noticing is mainly the first stage of learning. Other theorists have highlighted that during reading, the readers do not notice unfamiliar words and vocabulary learning will not happen (Azari, 2012). Therefore finding specific techniques which attracts the attention of learners and provokes noticing seems to be beneficial. Researchers believe that glossing is a way that helps learners to notice vocabularies which appear in reading materials. According to Yanguas (2005), "glosses do not interrupt the reading process as much, since the definition is easily available in the text" (p. 49). 
There are different forms of glosses such as pictures, animations, videos and sounds which can be employed in a variety of situations for the purpose of activating the background knowledge, mental images and the subconscious layers of the learner's mind. Also, Dual-coding theory proposed by Paivio (1971) supports the advantage of multimedia glosses and the effectiveness of text-plus-picture type of vocabulary annotation. In dual-coding theory, the information is received through two channels of verbal and visual in order to construct meaning. Therefore, learning is even more enhanced (Clark \& Paivio, 1991; Mayer \& Sims, 1994). In other words, verbal learning is more effective when it is accompanied by nonverbal or visual learning.

\section{Literature Review}

Numerous studies on the impact of glosses on vocabulary learning have been conducted. Some studies have revealed that the use of glossing is more helpful for comprehending texts and learning vocabulary items than having no glosses. Some other researches revealed no difference between the effects of various glosses on vocabulary learning.

Kost, Foss, \& Lenzini (1999) investigated the effects of pictorial and textual glosses and their combination on incidental vocabulary growth of foreign language learners in printed materials. They used subjects from second-semester German classes and made them read a narrative text passage under one of three marginal gloss conditions: textual gloss (English translation); pictorial gloss; and text and pictures in the gloss. Then they performed three types of tasks; a production task of providing English translations for the given words, a picture recognition task of choosing a correct picture of the word in question, and a word recognition task of choosing the correct English translation of the word in question. Subjects were tested both immediately following and two weeks after the reading. Support was found for the hypothesis that subjects utilizing a combination of text and pictures in the gloss would outperform subjects under the other two gloss conditions on the recognition of target words on both short-term memory and retention.

In Another study Yeh \& Wang (2003) investigated the effectiveness of three types of vocabulary annotations on vocabulary learning for EFL college students in Taiwan: text annotation only, text plus picture, and text plus picture and sound. The result of this study which was conducted on 82 university students in Taiwan showed that the version with text plus picture was the most effective type of vocabulary annotation.

Jacobs, Dufon, and Fong (1994) investigated the effect of vocabulary glossing on recall and vocabulary learning, as well as learners' preferences as to glossing. The subjects consisted of 85 native speakers of English studying Spanish at the university level. They were experimented on three treatment conditions: (1) control group (no glosses), (2) the 1st treatment group (English glosses), and (3) the 2nd treatment group (Spanish glosses). The findings of the study revealed that the performance of the two groups receiving the glosses was significantly better on a vocabulary test administered immediately after the treatment. The study revealed no difference between L1 and L2 glosses.

A similar study was done by Plass et al (1998) in which the effect of different gloss types was examined in a multimedia environment. He made English-speaking College students who were enrolled in a German course read a 762-word German language story presented by a computer program. For key words in the story, students could choose to see a translation on the screen in English (i.e., verbal annotation) or view a picture or video clip representing the word (i.e., visual annotation), or both. Results of definition supply tests indicated the superiority of selecting text and picture over selecting text and video. The performance of subjects who selected verbal and visual glosses was the best while that of those who selected none was the worst.

Yoshii (2006) examined the effectiveness of L1, L2, and pictorial glosses on incidental vocabulary learning in a multimedia environment. A total of 195 university students were asked to read a390-word text including 14 target words under four gloss conditions: L1 text only, L2 text only, L1 text-picture, and L2 text-picture. The final tests including a production test in which subjects provided the definition of the 14 target words in L1 and a recognition test in which they chose the appropriate meaning out of the four Choices written in the L2 showed that the picture groups outperformed the text groups on the definition supply tests. On recognition tests, L1 text group remembered words better than other groups. Findings showed that the effect of additional visual cues on vocabulary learning may rely on the nature of the tasks given.

In another study, Zoi, Bellou, and Mikropoulos (2011) investigated the effects of special designed multimedia glosses on vocabulary learning in German as a second language with elementary school pupils. The gloss involved annotations of unknown words in three representations: text translation from German into Greek, presentation of the word in German and its translation pronounced in Greek, and word interpretation by using a picture. Thirty one pupils of ages 10-11 years interacted with the multimedia gloss and participated in computer-based learning activities. The outcomes on vocabulary learning were positive, and the majority of pupils preferred the aural annotations of the unknown words. The attitude of all pupils towards use of the multimedia gloss and activities was also positive.

In a related study, $\mathrm{Xu}$ (2010) compared the effects of different gloss conditions on incidental word acquisition through reading. 103 participants were assigned to read a text composed of 774 words with 18 target words under one of the three conditions: six words were glossed in Chinese, six in English and six in both Chinese and English. The results of a text comprehension test, an immediate vocabulary test, and a delayed test one week later revealed that 1) A better text comprehension will result in a higher rate of incidental word acquisition, 2) L1 and L2 (Chinese and English) glosses is the most useful type of glossing for enhancement of vocabulary gain and vocabulary retention, 3) L1 (Chinese) gloss is the most useful gloss in vocabulary gain but it is the least useful in vocabulary retention, and 4) L2 (English) gloss is the weakest gloss for enhancement of vocabulary gain. 
In summary, results of studies indicate that the use of glosses aids incidental vocabulary learning. Also the combination of textual and visual glosses has a more beneficial effect on comprehension and vocabulary learning than either type in isolation.

\section{Methodology}

The present study examines the effect of glosses on incidental vocabulary learning. In so doing, the following research questions are formulated:

1. Does textual gloss improve the incidental vocabulary knowledge of learners in comparison to pictorial gloss?

2. Does textual gloss improve the incidental vocabulary knowledge of learners in comparison to combination of textual and pictorial gloss?

3. Does pictorial gloss improve the incidental vocabulary knowledge of learners in comparison to combination of textual and pictorial gloss?

4. To what extent do various glosses result in the improvement of the vocabulary knowledge of the learners?

\subsection{Participants}

Seventy learners who learn English as a foreign language at a private Language Institute in Karaj, Iran were initially chosen as participants. According to their scores on a Key English Test 45 of them were selected from 70 . The participants are both male and female and their ages range from 8 to 14 . The participants are at low-intermediate proficiency level.

\subsection{Instruments}

The following instruments and materials were used in order to conduct the study:

First, to guarantee the homogeneity of the participants with regard to their language proficiency the Key English Test (KET) which was developed in 2009 was used. Key English Test is based on language used in real life situations. The KET test of this study included 20 items. The test was administered to 70 learners. Then 45 students who were homogeneous were selected for the treatment.

Then, ten texts were selected from Oxford Word Skills (basic) by Gairns and Redman (2008) for the experiment. There were unfamiliar and unknown vocabularies in each text that were bolded and glossed in three forms: pictorial, textual, and pictorial-textual glosses.

Before the treatment, the students were administered a vocabulary pre-test. This test contained a list of words for which the participants were supposed to write the Persian equivalents. These words were the bolded vocabularies from the texts which were prepared for the treatment. Then the familiar and known words by the students were omitted from the posttest.

The last instrument was a post-test. It was a teacher-made test of vocabulary which included thirty fill-n-blanks questions. 30 sentences were selected from the dictionary and in each sentence there was a blank space. The Persian equivalents of words were written and the participants were required to write the missing target words.

\subsection{Procedure}

This study was conducted in a private Language Institute in Karaj, Iran. To conduct this research 70 learners who were learning English as a foreign language were selected. In order to make sure that the participants are homogeneous with regard to their language proficiency, a Key English Test (KET) was administered to all 70 learners. This test comprised of 20 items for which the learners had to provide the correct answer. Then the standard $\mathrm{Z}$ score was calculated and those participants whose standard scores were between -1 and +1 were included in this study. Eventually based on students' performance on the test and their results, 45 students were homogeneous and were chosen from the total number of 70 for the treatment. 25 of the subjects were removed from the study.

Then the participants were given a pretest before the treatment. It was a vocabulary test which contained a list of English words. The subjects were asked to provide the Persian equivalents of the words. These words were the bolded words taken from the reading texts. The aim of this test was to find out which vocabularies were known to the learners and thus omit them from the posttest. The words that were unknown or unfamiliar to a great number of participants were considered as unknown target words. Later these words were used in the vocabulary post-test.

Ten texts from Oxford Word Skills (basic) by Gairns and Redman (2008) were selected for the experiment. In each text the unfamiliar and unknown words were bolded so the students' attention was drawn to the target words. And then they were glossed in three different ways: pictorial glosses, textual glosses and pictorial-textual glosses.

45 participants were randomly assigned into three groups: pictorial gloss group, textual gloss group, and pictorialtextual gloss group. Each group consisted of 15 students.

For the pictorial group, the related pictures of the bolded unfamiliar words were searched on the internet or were adapted from Oxford Picture Dictionary (OPD) by Jayme Adelson-Goldstein and Norma Shapiro (2008) and were printed in the text. For the textual group, using Oxford Elementary Learner's Dictionary and Longman Dictionary, the definitions and meanings of the bolded vocabularies were carefully chosen and they were presented in the text. Then for the pictorial-textual group, a combination of pictures and definitions of bolded words were provided in the texts for the learners. The glosses were printed in the margins and below the texts. 
The experiment was carried out in ten sessions. Every session lasted 30 to 45 minutes. Classes were held once in a week. In the first group the participants had the opportunity to have pictorial gloss and researcher taught with pictures. In the second group they were provided with textual gloss and in the third group the participants had access to texts with both types of glosses that is pictorial and textual glosses. The researcher herself taught the three groups. The groups had the same condition in terms of hours of instruction, number of texts and vocabularies. So the performances of 45 subjects in terms of vocabulary learning in three groups were compared and analyzed.

Then at the end of the treatment, a posttest of vocabulary was administered to the learners to measure vocabulary learning and the amount of progress made by students. All the students in three groups took the post test. It was a fill-inblanks vocabulary test which contained 30 items. 30 sentences were selected and there was a blank space in each sentence. The blanks were the glossed words taught during the treatment. The Persian translations of target words were provided and the students had to write the English target words.

It was a teacher-made test so this test was first piloted with 22 students before the main test. They were from the same language institute and had the same characteristics of the participants. These students who took the test in the pilot study were excluded from the main post-test because the test was presented to them beforehand. This task was done to estimate the reliability of the teacher-made test. Item characteristics including item facility (IF) and item discrimination (ID) were determined and then KR-21 formula was utilized to estimate the reliability of the test which turned out to be 0.88. And in the end the poor items were omitted and 30 items were prepared for the post-test.

The data gathered from the research were submitted to statistical analysis.

\section{Data Analysis}

\subsection{Analyzing Homogeneity of Data}

To homogenize students, initially a 20 -item test was administered to 70 subjects. Then the scores of this test were processed by the SPSS software and the standard Z score was calculated for the scores. Standard scores between -1 and +1 are regarded as homogenous. As a result, 45 out of 70 subjects who participated in the test were considered as homogenous and they were divided into three groups. Each group consisted of 15 students and one way of vocabulary learning was tested in these groups.

\subsection{Comparing textual gloss and pictorial gloss in vocabulary learning}

In order to investigate the point that whether there is a significant difference between textual gloss and pictorial gloss in students' vocabulary learning improvement or not, T-test with two independent samples is used, because the T-test for two independent samples compares the means of two groups of respondents.

Table 1. Result of Descriptive Statistics Vocabulary Learning: textual gloss and pictorial gloss

\begin{tabular}{llllll}
\hline & group & $\mathrm{N}$ & Mean & Std. Deviation & Std. Error Mean \\
\hline \multirow{2}{*}{ Vocabulary Learning } & pictorial & 15 & 12.27 & 1.710 & .441 \\
& textual & 15 & 13.73 & 1.223 & .316 \\
\hline
\end{tabular}

The table above shows that the mean of pictorial gloss in vocabulary learning is 12.27 and mean of textual gloss in vocabulary learning is 13.73 and it can be inferred that the difference between means of these two groups is 1.46 . To decide whether this mean difference is significant or not, the results of the table 2 can be used.

Table 2. Result of Independent Sample T-Test in Vocabulary Learning: between textual gloss and pictorial gloss

\begin{tabular}{|c|c|c|c|c|c|c|c|c|}
\hline \multicolumn{9}{|c|}{$\begin{array}{l}\text { Levene's Test for t-test for Equality of Means } \\
\text { Equality of } \\
\text { Variances }\end{array}$} \\
\hline \multirow[t]{2}{*}{$\bar{F}$} & \multirow[t]{2}{*}{ Sig. } & \multirow[t]{2}{*}{$\mathrm{t}$} & \multirow[t]{2}{*}{$\mathrm{df}$} & \multirow[t]{2}{*}{$\begin{array}{l}\text { Sig. (2- } \\
\text { tailed) }\end{array}$} & \multirow[t]{2}{*}{$\begin{array}{l}\text { Mean } \\
\text { Difference }\end{array}$} & \multirow[t]{2}{*}{$\begin{array}{l}\text { Std. Error } \\
\text { Difference }\end{array}$} & \multicolumn{2}{|c|}{$\begin{array}{l}95 \% \text { Confidence } \\
\text { Interval of the } \\
\text { Difference }\end{array}$} \\
\hline & & & & & & & Lower & Upper \\
\hline \multirow[t]{2}{*}{4.738} & .038 & -2.702 & 28 & .012 & -1.467 & .543 & -2.578 & -.355 \\
\hline & & -2.702 & 25.351 & .012 & -1.467 & .543 & -2.584 & -.350 \\
\hline
\end{tabular}

For investigating whether there is a significant difference or not, in the case that level of significance of T-test is less than 0.05 ( sig< 0.05), then we can infer that there is a significant difference between the two groups. On the other hand if the significance level for Levene's test is higher than 0.05 , we use the results of the first row of the Independent Sample T-test table which accepts the assumption of equality of variances. But if the level of significance for this test is less than 0.05 , then we use the results of the second row of table which accepts the assumption of inequality of variances for the two groups. So in the above table, the results of the second row are used. According to the table above, with $95 \%$ confidence level and 0.05 standard error, the level of significance ( $p$ value) is less than 0.05 (sig=0.012). So it can be inferred that difference between the means in textual gloss group in vocabulary learning and pictorial gloss 
group in vocabulary learning is significant. It means that there is difference between textual gloss group and pictorial gloss group in vocabulary learning. Also we can say that since the mean of textual gloss is higher than the mean of pictorial gloss, so the effect of textual gloss in vocabulary learning is greater than pictorial gloss.

\subsection{Comparison of textual-pictorial gloss and pictorial gloss in vocabulary learning}

To investigate if there is a significant difference between textual-pictorial gloss and pictorial gloss in students' vocabulary learning or not, T-test with two independent samples is used. Since the T-test for two independent samples compares the means of two groups of respondents.

Table 3. Result of Descriptive Statistics Vocabulary Learning: pictorialtextual gloss and pictorial gloss

\begin{tabular}{llllll}
\hline & group & $\mathrm{N}$ & Mean & Std. Deviation & Std. Error Mean \\
\hline \multirow{2}{*}{ Vocabulary Learning } & pictorial & 15 & 12.27 & 1.710 & .441 \\
& pictorialtextual & 15 & 16.40 & 1.183 & .306 \\
\hline
\end{tabular}

The above table indicates that the mean of pictorial gloss in vocabulary learning is 12.27 and the mean of textualpictorial gloss in vocabulary learning is 16.40 and we can say that the difference between the means of these two groups is 4.13 . To check for the significance of the mean difference, the result of the table 4 is used.

Table 4. Result of Independent Sample T-Test in Vocabulary Learning: between pictorialtextual gloss and pictorial gloss

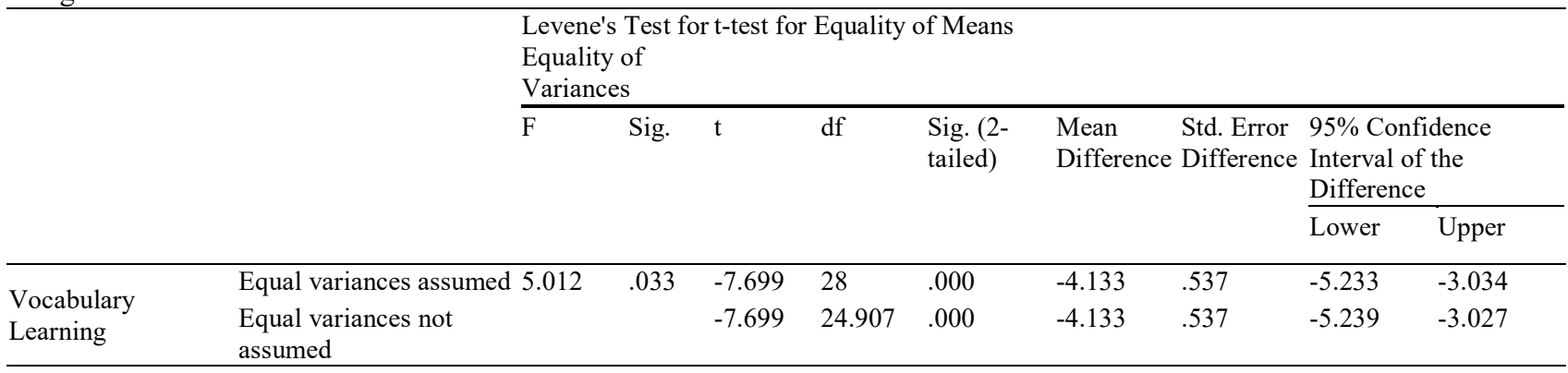

To determine whether there is a significant difference or not, if the significance level of T-test is less than 0.05 (sig< 0.05), then we can conclude that there is a significant difference between the two groups. If the significance level for Levene's test is higher than 0.05 , we will use the results of the first row of the Independent Sample T-test table which accepts the assumption of equality of variances. But if the level of significance for this test is less than 0.05 , then we use the results of the second row of table which accepts the assumption of inequality of variances for the two groups. Therefore we should use the results of the second row in the above table. According to the table above, with $95 \%$ confidence level and 0.05 standard error, the level of significance ( $p$ value) is less than 0.05 (sig=0.000). So we can conclude that the mean difference between textual-pictorial gloss in vocabulary learning and pictorial gloss in vocabulary learning is significant. This means that there is difference between pictorial gloss and pictorial-textual gloss in vocabulary learning. And also since the mean of textual-pictorial gloss is higher than the mean of pictorial gloss, so the effect of textual-pictorial gloss is greater than pictorial gloss in vocabulary learning.

\subsection{Comparison of textual-pictorial gloss and textual gloss in vocabulary learning}

To investigate whether there is a significant difference between textual gloss and textual-pictorial gloss in the improvement of students' vocabulary learning or not, the independent two-sample T-test is used, since the T-test for two independent samples compares the means of two groups of respondents.

Table 5. Result of Descriptive Statistics Vocabulary Learning:pictorialtextual gloss and textual gloss

\begin{tabular}{llllll}
\hline & group & $\mathrm{N}$ & Mean & Std. Deviation & Std. Error Mean \\
\hline \multirow{2}{*}{ Vocabulary Learning } & textua & 15 & 13.73 & 1.223 & .316 \\
& pictorialtextual & 15 & 16.40 & 1.183 & .306 \\
\hline
\end{tabular}

The finding of the above table reveals that the textual gloss's mean in vocabulary learning is 13.73 and the mean of textual-pictorial gloss in vocabulary learning is 16.40 and we can say that the difference between the means of these two groups is 2.66. To determine whether the mean difference is significant or not, the results of the table 6 is used. 


\begin{tabular}{|c|c|c|c|c|c|c|c|c|c|c|}
\hline & & \multicolumn{9}{|c|}{$\begin{array}{l}\text { Levene's Test for t-test for Equality of Means } \\
\text { Equality of } \\
\text { Variances }\end{array}$} \\
\hline & & \multirow[t]{2}{*}{$\overline{\mathrm{F}}$} & \multirow[t]{2}{*}{ Sig. } & \multirow[t]{2}{*}{$\mathrm{t}$} & \multirow[t]{2}{*}{ df } & \multirow[t]{2}{*}{$\begin{array}{l}\text { Sig. (2- } \\
\text { tailed) }\end{array}$} & \multirow[t]{2}{*}{$\begin{array}{l}\text { Mean } \\
\text { Difference }\end{array}$} & \multirow[t]{2}{*}{$\begin{array}{l}\text { Std. Error } \\
\text { Difference }\end{array}$} & \multicolumn{2}{|c|}{$\begin{array}{l}95 \% \text { Confidence } \\
\text { Interval of the } \\
\text { Difference }\end{array}$} \\
\hline & & & & & & & & & Lower & Upper \\
\hline \multirow{2}{*}{$\begin{array}{l}\text { Vocabulary } \\
\text { Learning }\end{array}$} & Equal variances assumed & .062 & .806 & -6.070 & 28 & .000 & -2.667 & .439 & -3.567 & -1.767 \\
\hline & $\begin{array}{l}\text { Equal variances not } \\
\text { assumed }\end{array}$ & & & -6.070 & 27.970 & .000 & -2.667 & .439 & -3.567 & -1.767 \\
\hline
\end{tabular}

To examine whether there is a significant difference or not, if the significance level of T-test is less than 0.05 (sig< 0.05 ), then we come to conclusion that there is a significant difference between the two groups. If the significance level for Levene's test is higher than 0.05, we will use the results of the first row of the Independent Sample T-test table which accepts the assumption of equality of variances. But if the level of significance for this test is less than 0.05 , in that case we will use the results of the second row of the table which accepts the assumption of inequality of variances for the two groups. So in the above table, the results of the second row must be used. According to the table above the level of significance ( $\mathrm{p}$ value) is less than 0.05 ( $\mathrm{sig}=0.000$ ), with $95 \%$ confidence level and 0.05 standard error. So we conclude that the mean difference between textual-pictorial gloss in vocabulary learning and textual gloss in vocabulary learning is significant which represents that there is difference between textual-pictorial gloss and textual gloss in vocabulary learning. And also since the mean of textual-pictorial gloss is higher than the mean of textual gloss, so the effect of textual-pictorial gloss is greater than the textual gloss in vocabulary learning.

\subsection{F-test, one-way analysis of variance or ANOVA}

F-test or one-way analysis of variance is used for testing the mean difference of one variable among more than two groups (three or more).

Since in this study we want to examine the differences in vocabulary learning among three groups of pictorial gloss, textual gloss and pictorial-textual gloss we use F-test.

Table 7. Descriptive Statistics for the ANOVA on Vocabulary Learning

\begin{tabular}{|c|c|c|c|c|c|c|c|c|}
\hline & \multirow[t]{2}{*}{$\mathrm{N}$} & \multirow[t]{2}{*}{ Mean } & \multirow[t]{2}{*}{$\begin{array}{r}\text { Std. } \\
\text { Deviation }\end{array}$} & \multirow[t]{2}{*}{ Std. Error } & \multicolumn{2}{|c|}{$\begin{array}{c}\text { 95\% Confidence Interval for } \\
\text { Mean } \\
\end{array}$} & \multirow[t]{2}{*}{ Minimum } & \multirow[t]{2}{*}{ Maximum } \\
\hline & & & & & Lower Bound & Upper Bound & & \\
\hline pictorial & 15 & 12.27 & 1.710 & .441 & 11.32 & 13.21 & 10 & 15 \\
\hline textual & 15 & 13.73 & 1.223 & .316 & 13.06 & 14.41 & 12 & 16 \\
\hline pictorialtextual & 15 & 16.40 & 1.183 & .306 & 15.74 & 17.06 & 15 & 18 \\
\hline Total & 45 & 14.13 & 2.201 & .328 & 13.47 & 14.79 & 10 & 18 \\
\hline
\end{tabular}

Table 7 shows the descriptive statistics of pictorial gloss, textual gloss and pictorial-textual gloss. It shows that the mean of pictorial gloss in vocabulary learning is 12.27 , the mean of textual gloss in vocabulary learning is 13.73 and the mean of textual-pictorial gloss in vocabulary learning is 16.40 . Thus, it can be inferred that there is a difference among the means of these three groups and the F-test results can be used to determine whether the mean difference is significant or not.

Table 8. ANOVA on Vocabulary Learning

\begin{tabular}{llllll}
\hline & Sum of Squares & df & Mean Square & F & Sig. \\
\hline Between Groups & 131.733 & 2 & 65.867 & 33.957 & .000 \\
Within Groups & 81.467 & 42 & 1.940 & & \\
Total & 213.200 & 44 & & & \\
\hline
\end{tabular}

As it can be seen in the table 8 , we can say that with $95 \%$ confidence interval and 0.05 standard error, the level of significance for F-test is less than $0.05(\mathrm{~F}=33.95$, sig=0.000). Therefore the mean difference among three groups of pictorial-textual gloss, textual gloss and pictorial gloss in vocabulary learning is significant. 
For examining and two by two comparing (comparison pair) the significance of difference among the means of the groups, Scheffe test is used.

Table 9. Multiple comparisons for the ANOVA on vocabulary learning

\begin{tabular}{|c|c|c|c|c|c|c|c|}
\hline & \multirow[t]{2}{*}{ (I) group } & \multirow[t]{2}{*}{ (J) group } & \multirow{2}{*}{$\begin{array}{l}\text { Mean Difference } \\
(\mathrm{I}-\mathrm{J})\end{array}$} & \multirow[t]{2}{*}{ Std. Error } & \multirow[t]{2}{*}{ Sig. } & \multicolumn{2}{|c|}{ 95\% Confidence Interval } \\
\hline & & & & & & Lower Bound & Upper Bound \\
\hline \multirow{2}{*}{ Scheffe } & \multirow{2}{*}{ pictorial } & textual & $-1.467^{*}$ & .509 & .022 & -2.76 & -.18 \\
\hline & & pictorialtextual & $-4.133^{*}$ & .509 & .000 & -5.42 & -2.84 \\
\hline & \multirow{2}{*}{ textual } & pictorial & $1.467^{*}$ & .509 & .022 & .18 & 2.76 \\
\hline & & pictorialtextual & $-2.667^{*}$ & .509 & .000 & -3.96 & -1.38 \\
\hline & \multirow{2}{*}{ pictorialtextual } & pictorial & $4.133^{*}$ & .509 & .000 & 2.84 & 5.42 \\
\hline & & textual & $2.667^{*}$ & .509 & .000 & 1.38 & 3.96 \\
\hline
\end{tabular}

*. The mean difference is significant at the 0.05 level.

Table 9 represents the results of the scheffe test. As previously stated, scheffe test is used for pair comparison between the means of groups. In the first part (row) of the table, the pictorial gloss is compared with textual gloss and textualpictorial gloss. In the second row, the textual gloss is compared with pictorial gloss and pictorial-textual gloss. And in the third row, pictorial-textual gloss is compared with textual gloss and pictorial gloss. The results indicate that with $95 \%$ confidence interval and 0.05 error, the level of significance for scheffe test in the whole comparison is less than 0.05. Therefore the mean difference of vocabulary learning between two groups which are compared in each row is significant. In other words, there is difference in vocabulary learning between pictorial gloss in comparison to textual gloss and textual-pictorial gloss, there is difference in vocabulary learning between textual gloss in comparison to pictorial gloss and textual-pictorial gloss, there is difference in vocabulary learning between textual-pictorial gloss in comparison to textual gloss and pictorial gloss.

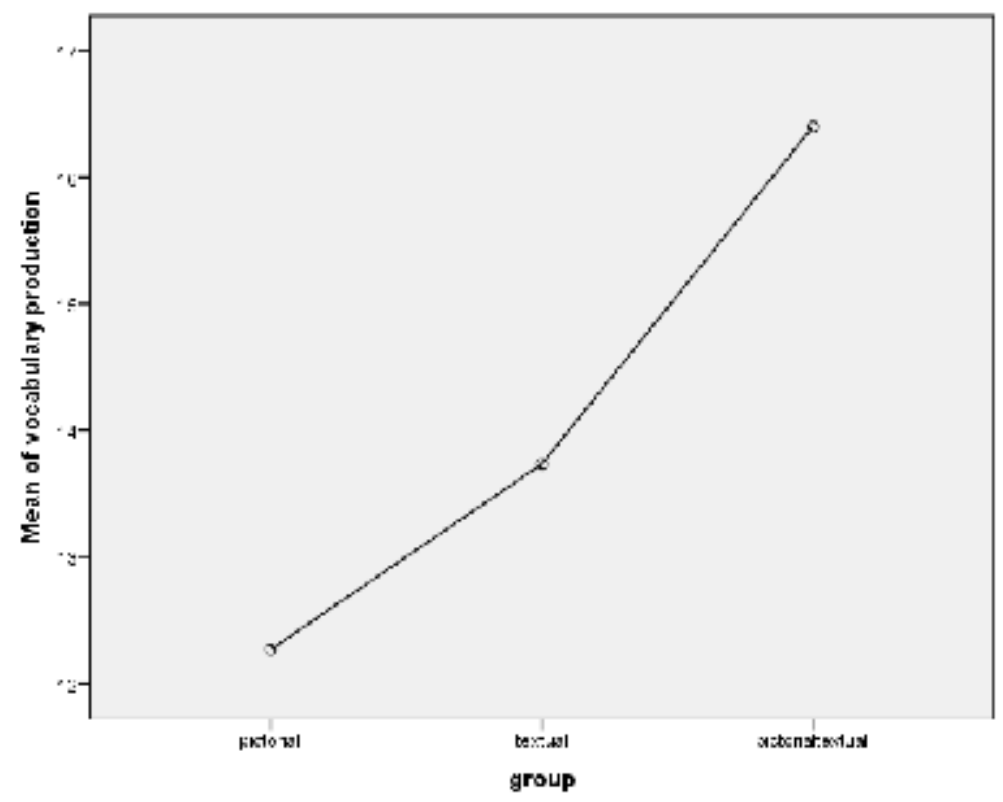

Mean difference of textual-pictorial gloss and textual gloss and pictorial gloss in vocabulary learning is also shown in the chart above. According to the chart, the effect of textual-pictorial gloss in vocabulary learning is greater than textual gloss and the effect of textual gloss is greater than pictorial gloss.

\section{Discussion and Conclusion}

This research tried to investigate and examine the effects of glosses that is; textual, pictorial, and textual-pictorial on incidental vocabulary learning. The information discovered from the present study revealed that glosses have positive effects on incidental vocabulary learning. This study confirmed that using two different glosses which are pictures and definitions results in better responses to the vocabulary tests. Also there was a significant difference among gloss groups.

The result of this study is in accordance with Kost, Foss, \& Lenzini (1999); Tabatabaei and Shams (2011); Shahrokni (2009); Chun \& Plass, 1996; Al-Seghayer, 2001; Yeh \& Wang, 2003 that suggested that the impact of the mixture of text and picture annotation on vocabulary learning was better because the students received two modes of input, which are verbal and visual and the groups with glosses learned the new words better than other groups. 
Similarly Yanguas (2009) indicated that combination of textual and visual glosses has better impact on vocabulary learning than these gloss types separately.

With regard to the first research question, the results of the research reveal that the participants who were exposed to textual glosses did better than those who received pictorial glosses, and there was a significant difference in the performance of textual gloss group and performance of pictorial gloss group in vocabulary learning

Concerning the second research question, which questioned the improvement of the incidental vocabulary knowledge of learners in textual gloss group in comparison to combination of textual and pictorial gloss group, the group exposed to combination of pictorial and textual glosses outperformed the textual gloss group. Moreover the results revealed that there was a meaningful difference between the performance of the students in the pictorial-textual gloss groups and the performance of the textual gloss group in vocabulary learning.

In response to the third research question in which the pictorial gloss group and pictorial-textual gloss group are compared, the combination of textual and pictorial gloss group performed better than the pictorial gloss group. Also a significant difference between these two groups was found.

Evenetually, concerning the fourth question of this research, the combination gloss group significantly outperformed the others.

In the combination gloss group, that participants were given texts by textul gloss together with the picture, students made use of combination gloss group. The presence of both text and picture had a cognitive impact on vocabulary learning of the participants.

According to the results, it could be seen that the mean of the scores for the pictorial-textual gloss group is the highest among the three and glossing with the combination of pictures and definitions is the most effective. The type of gloss only with definitions and meanings is the second. And glossing with pictures falls to the third place. That is to say, a significant difference among the three types of glossing exists.

To conclude, glossing of unfamiliar words is easy to comprehend and recall. Also students may be less worried while reading the texts because of the presence of the glosses.

As proved by the quantitative findings of this study, when a combination of verbal and visual channels is employed, learning of vocabulary occurs better.

In other words the combination of picture and definition, which means using both verbal and visual systems, caused profound processing of unfamiliar words. And vocabulary remains in long term memory when we use static picture and definition at the same time.

\section{Implications}

The research is significant for teachers and material developers. The findings give the chance to teachers to help students improve their vocabulary acquisition. Teachers, who try to seek new techniques for teaching unknown vocabularies in the classes, can employ and depend on glosses to increase and improve learning experience for learners. The findings make teachers aware of the importance of annotations and glosses so that they would not skip them in their teaching activities. Also this study has implications for material designers. Material developers can prepare suitable and appropriate reading materials employing different kinds of glosses for the troubling vocabulary items which proved to have positive impact on vocabulary learning and may promote learning.

\section{References}

Al-Seghayer, K. (2001). The effect of multimedia annotation modes on L2 vocabulary acquisition: A comparative study. Language learning and Technology, 5(1), 202-232.

Azari, F. (2012). Review of effects of textual glosses on incidental vocabulary learning, International Journal of Innovative Ideas, 12 (2), 13-24.

Clark, J \& Paivio, A. (1991). Dual coding theory and education. Educational Psychology Review, 3(3), 149-210.

Hong, X. (2010). Review of effects of glosses on incidental vocabulary learning and reading comprehension. Chinese Journal of Applied linguistics, 33(1)

Hulstijn, J. H., Hollander, M., \& Greidanus, T. (1996). Incidental vocabulary learning by advanced foreign language students: The influence of marginal glosses, dictionary use, and reoccurrence of unknown words. The Modern Language Journal, 80 (3), 327-394.

Jacobs, G. M., DuFon, P. \& Fong C. H. (1994). L1 and L2 vocabulary glosses in L2 reading passages: Their effectiveness for increasing comprehension and vocabulary knowledge. Journal of Research in Reading 17, 19-28.

Kost, C. R., Foss, P. \& Lenzini, J. J. 1999. Textual and pictorial glosses: Effectiveness on incidental vocabulary growth when reading in a foreign language. Foreign Language Annals, 32 (1), 89-113.

Lomicka, L. (1998). To gloss or not to gloss an investigation of reading comprehension online, language learning and technology. Language learning and technology, 1(2), 41-50.

Mayer, R \& Sims,V. (1994). For whom is a picture worth a thousand words? Extensions of a dual- coding theory of multimedia learning. Journal of Educational Psychology, 86(3), 389-401. 
Nation, I. S. P. (2002). Learning vocabulary in another language. The Cambridge Applied Linguistics Series. Cambridge University Press.

Pak, J. (1986). The effect of vocabulary glossing on ESL reading comprehension.. Unpublished

Plass, J. L., Chun, D. M., Mayer, R. E., \& Leutner, D. (1998). Supporting visual and verbal learning preferences in a second-language multimedia learning environment. Journal of Educational Psychology, 90 (1), 25-36.

Roby, W. B. (1999). What's in a gloss? Language Learning and Technology, 1, 94-101.

Segler, T. M. 2001. PhD research proposal: second language vocabulary acquisition and learning strategies in ICALL environment.

Shahrokni, A. (2009). Second language incidental vocabulary learning: The effect of online textual, pictorial, and textual pictorial glosses. Teaching English as a Second or Foreign Language, 13(3), 1-17.

Sonbul, S and Schmitt, N. (2010). Direct teaching of vocabulary after reading: is it worth the effort? ELT Journal, 64(3), 253-260.

Tabatabaei, O \& Shams, N. (2011). The effect of multimedia glosses on online computerized L2 text comprehension and vocabulary learning of Iranian EFL learners. Journal of Language Teaching and Research, 2(3), 714-725.

$\mathrm{Xu}, \mathrm{X}$. (2010). The effects of glosses on incidental vocabulary acquisition in reading. School of Foreign Languages. Journal of Language Teaching and Research, 1(2), 117-120.

Yanguas, I. (2005). Type of multimedia gloss and L2 proficiency: A computer-based study. Paper presented at Second Language Research Forum, (SLRF), New York, NY.

Yeh ,Y\& Wang, C. (2003). Effects of multimedia vocabulary annotations and learning styles on vocabulary learning. CALICO Journal, 21(1), 131-144.

Yoshii, M. (2006). L1 and L2 glosses: Their effects on incidental vocabulary learning. Language Learning \& Technology, 10 (3), 85-101.

Zoi, M; Bellou, I, \& Mikropoulos, T. (2011). Second language teaching in elementary school with a multimedia gloss. Paper presented at the International Conference on Languages, Literature, \& Linguistics, Singapore, IPEDR, 26. 